\title{
ADRENAL INSUFFICIENCY DUE TO X-LINKED ADRENOLEUKODYSTROPHY DIAGNOSED IN LATE ADULTHOOD
}

\author{
M.S Gogorza Pérez, G. Serra Soler, A. Jimenez Portilla, M. Wos, H. García Fernández, I. Argüelles Jiménez, E. Mena Ribas, \\ S. Tofé Povedano, M. Codina Marcet, V. Pereg Macazaga. \\ Department of Endocrinology and Nutrition, Hospital Universitari Son Espases. Illes Balears. España
}

\section{INTRODUCTION}

X-linked adrenoleukodystrophy (X-ALD) is a rare condition presented mainly in males during childhood and early adulthood. It represents almost $10 \%$ of primary adrenal insufficiency (PAI) or Addison's disease cases.

\section{CLINICAL CASE}

A 67-year-old male was diagnosed at the age of 61 with PAI during testing for mesenteric paniculitis while admitted in Internal Medicine service. He was treated with hydrocortisone and referred to outpatient endocrinology clinic. The patient did not attend and restarted follow-up 6 years later.

His past medical history included dyslipidemia, anxiety and parkinson-like syndrome since 2012. He was taking hydrocortisone 20-5-5mg, with no mineralocorticoid. He had normal blood pressure with no significant changes between supine and orthostatic position. Blood tests showed normal levels of serum sodium, potassium and renin. Aldosterone was in the lower limit of normality (table 1). 21-hidroxilase antibodies were negative and the abdominal CT scan showed normal adrenal glands (Fig. 1). Due to the normality of these two tests, plasma levels of very long-chain fatty acids (VLCFA) were assessed; they were elevated (table 2).

Genetic study demonstrated a mutation in the ABCD1 gene: p.E292K(c.874G>A). Skin biopsy revealed high levels of VLCFA in fibroblasts and low levels of ALD- protein. MRI of the brain had no alterations in the white matter (Fig.2). DATscan exposed changes in the nigrostriatal pathway suggestive of Parkinson's disease. He satisfied the Addisononly phenotype.

The patient had a 24 year old son and a 30 year old daughter who wanted children. She presented high levels of plasma VLCFA and the genetic study revealed the same mutation as her father. She was referred to genetic counseling.
Table 1. Laboratory findings

\begin{tabular}{|l|c|c|}
\hline & Value & Normal Values \\
\hline Renin & $7,5 \mathrm{uU} / \mathrm{ml}$ & $4,2-59,7$ \\
\hline Aldosterone & $3,7 \mathrm{ng} / \mathrm{dl}$ & $3,7-21$ \\
\hline Sodium & $140 \mathrm{mEq} / \mathrm{L}$ & $136-145$ \\
\hline Potassium & $3,9 \mathrm{mEq} / \mathrm{L}$ & $3,6-5,3$ \\
\hline
\end{tabular}

Table 2. Long chain fatty acids

\begin{tabular}{|l|c|r|}
\hline & Value & Normal Values \\
\hline Behemic acid (C22:0) & $\mathbf{7 0 , 3}$ umol/L & $51,1-113,4$ \\
\hline Lignoceric acid (C24:0) & $\mathbf{1 0 9 , 5 ~ u m o l / L ~}$ & $44,3-92,4$ \\
\hline Hexacosanoic acid (C26:0) & $\mathbf{4 , 7} \mathbf{u m o l} / \mathrm{L}$ & $0,22-0,88$ \\
\hline Ratio sC24/C22 & $\mathbf{1 , 5 6}$ & $0,55-0,89$ \\
\hline Ratio sC26/C22 & $\mathbf{0 , 0 6 7}$ & $0,004-0,021$ \\
\hline
\end{tabular}

Figure 1. Abdominal CT scan

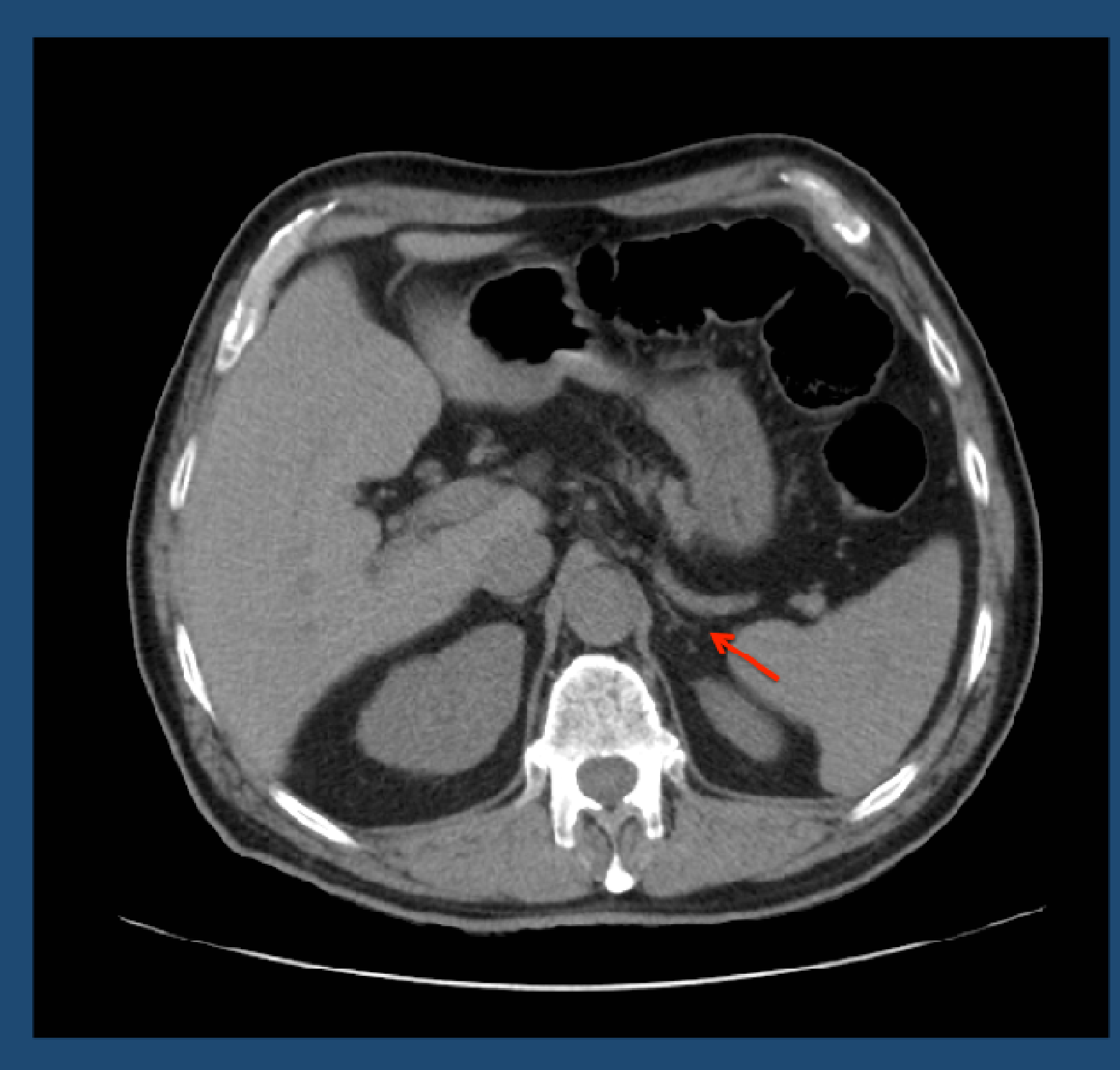

Figure 2. Brain MRI

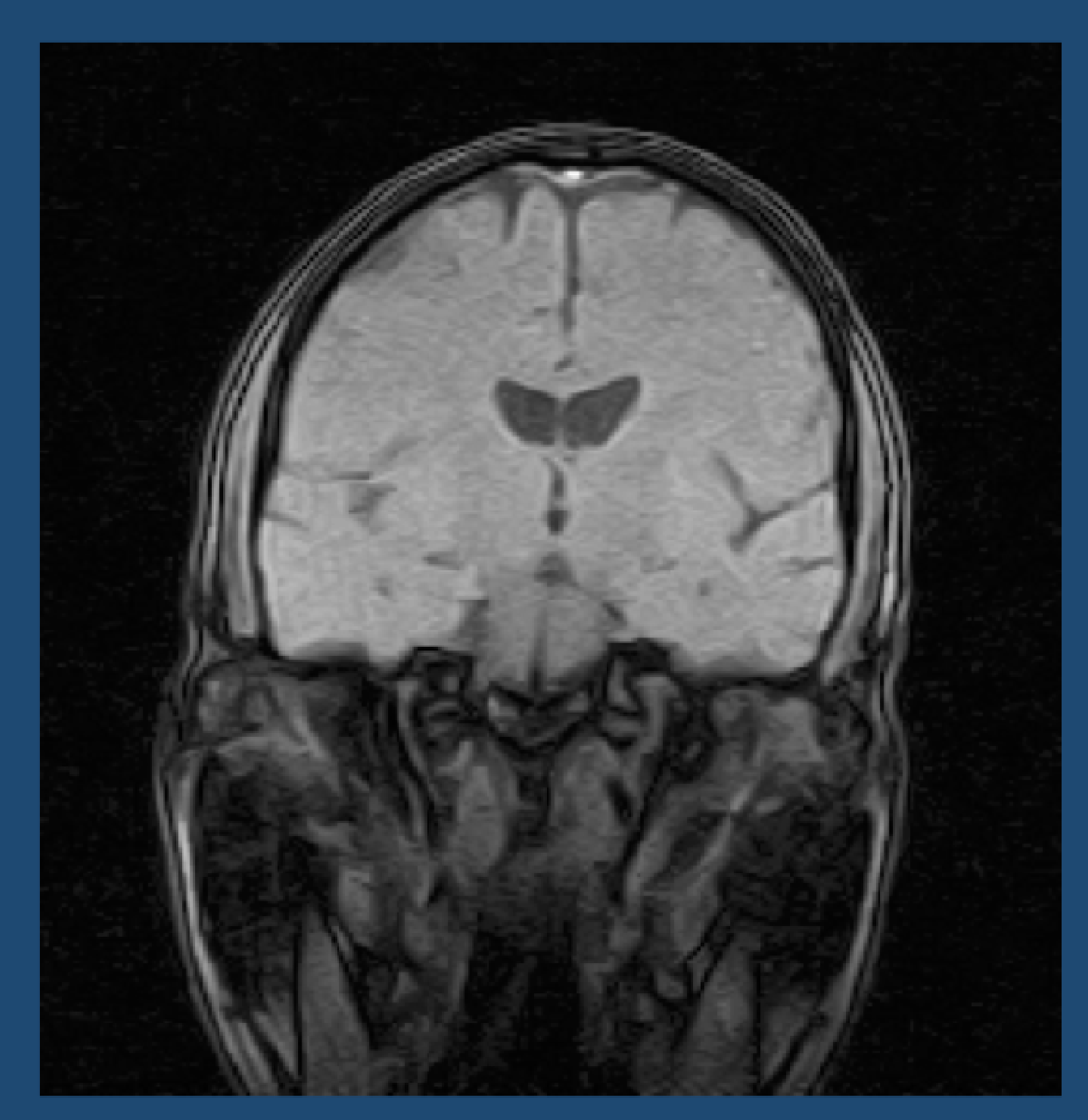

\section{CONCLUSION}

To consider X-ALD in males diagnosed with PAl at any age because of its implications, one very important being the transmission to offspring.

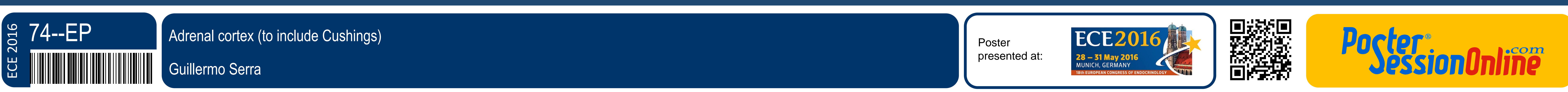

